\title{
Downhill esophageal varices: a therapeutic dilemma
}

\author{
Raja Chandra Chakinala ${ }^{1}$, Anila Kumar ${ }^{1}$, Jonathan E. Barsa ${ }^{2}$, Dhruv Mehta ${ }^{2}$ Khwaja F. Haq ${ }^{1}$, Shantanu \\ Solanki ${ }^{1}$, Virendra Tewari ${ }^{2}$, Wilbert S. Aronow ${ }^{3}$ \\ ${ }^{1}$ Division of General Medicine, Department of Medicine, ${ }^{2}$ Department of Gastroenterology and Hepatobiliary Diseases, ${ }^{3}$ Department of Cardiology, \\ Westchester Medical Center, New York Medical College, Valhalla, NY, USA \\ Correspondence to: Wilbert S. Aronow, MD, FACC, FAHA. Professor of Medicine and Director of Cardiology Research, Westchester Medical Center, \\ New York Medical College, Macy Pavilion, Room 141, Valhalla, NY 10595, USA. Email: wsaronow@aol.com.
}

\begin{abstract}
Esophageal varices can cause life-threatening complications and are most often a sequela of liver disease. Although a rare cause of gastrointestinal bleeding, downhill variceal bleeding secondary to superior vena cava (SVC) obstruction should be considered in the differential diagnosis for patients with upper gastrointestinal hemorrhage. We discuss two such cases of downhill esophageal varices presenting with hematemesis in patients with end stage renal disease and no history of cirrhosis. These varices were thought to be secondary to SVC occlusion caused by complications from previous dialysis catheters. However, their difficult anatomy posed a significant challenge to the therapeutic interventions.
\end{abstract}

Keywords: Downhill esophageal varices; gastrointestinal bleeding; superior vena cava obstruction (SVC obstruction)

Submitted Sep 28, 2018. Accepted for publication Nov 01, 2018.

doi: $10.21037 /$ atm.2018.11.13

View this article at: http://dx.doi.org/10.21037/atm.2018.11.13

\section{Introduction}

Downhill esophageal varices are commonly associated with superior vena cava (SVC) obstruction and are named based on their cephalad to caudal direction of blood flow. Located in the upper third or middle third of the esophagus, they represent a rare subset of acute esophageal variceal bleeding. Currently, there are no standard guidelines regarding the management of these varices. We present two cases of downhill esophageal varices found on upper endoscopy in patients undergoing evaluation of hematemesis (Table 1).

\section{Case presentation}

\section{Case 1}

A 56-year-old man with a past medical history of hematemesis requiring hospitalization and banding of esophageal varices in 2015, end-stage renal disease (ESRD) requiring hemodialysis (HD), rheumatoid arthritis, and peripheral vascular disease initially presented due to shortness of breath secondary to volume overload. His hospital course was complicated by one episode of hematemesis with a drop in hemoglobin $(\mathrm{Hgb})$ from a baseline of 7.5-8 to $6.7 \mathrm{~g} / \mathrm{dL}$. Upper endoscopy showed large varices in the proximal and middle third of the esophagus with no bleeding stigmata (Figure 1). Mildly erythematous mucosa was noted in the antrum of stomach, but no gastric varices were seen. The duodenal bulb and second part of the duodenum appeared normal. No intervention was done at the time of upper endoscopy given his recent clopidogrel use and no active source of bleeding. Ultrasound (US) of the abdomen showed normal liver echotexture, patent hepatic vessels with appropriate directional flow, no ascites, and normal inferior vena cava (IVC). US shear wave elastography showed mild to moderate liver fibrosis with a METAVIR score of F2-F3. Liver cirrhosis work- up including liver function tests, platelet count, autoimmune work-up, and viral hepatitis panel were normal. Computed tomography (CT) of the chest and abdomen with intravenous contrast was performed to evaluate for the source of esophageal varices, and showed chronic occlusion of the SVC and right brachiocephalic vein with extensive collateralization (Figure 2). There was early hyperenhancement within the 
Table 1 Characteristics of patients diagnosed with downhill esophageal varices

\begin{tabular}{|c|c|c|}
\hline Characteristics & Case 1 & Case 2 \\
\hline Sex & Male & Male \\
\hline Symptoms & Hematemesis & Hematemesis \\
\hline EGD findings & $\begin{array}{l}\text { Large varices in the proximal and middle third } \\
\text { of the esophagus with no bleeding stigmata }\end{array}$ & $\begin{array}{l}\text { Medium-sized varices in the proximal and mid esophagus with no } \\
\text { stigmata of bleeding }\end{array}$ \\
\hline Number of EGDs & Two & Three \\
\hline Intervention & Failed SVC stenting; band ligation & None \\
\hline
\end{tabular}

EGD, esophagogastroduodenoscopy; CT, computed tomography; SVC, superior vena cava; IVC, inferior vena cava.

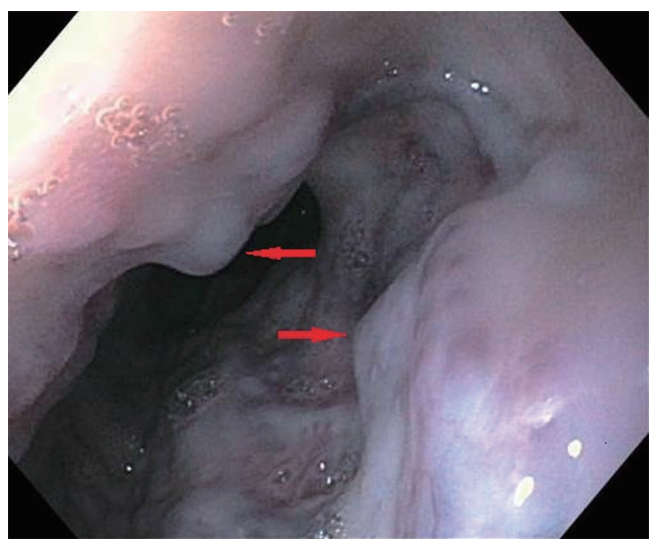

Figure 1 Upper endoscopy image showing large varices in in the proximal and middle third of the esophagus (red arrows).

hepatic segment 4 (hot quadrate sign), which is associated with chronic SVC thrombosis.

Vascular surgery attempted to place a stent in his SVC but could not pass a wire through the occlusion. The patient experienced recurrence of hematemesis one month later and underwent band ligation of an esophageal varix (Figure 3).

\section{Case 2}

A 56-year-old man with a past medical history of recurrent episodes of hematemesis (last upper endoscopy in 2014 showed no active bleeding sites), gastroparesis, diabetes mellitus type 2, ESRD on HD, and atrial flutter on warfarin initially presented with erythema over his arteriovenous fistula site. During the hospitalization, he had one episode of coffee ground emesis, approximately $90 \mathrm{~mL}$ in volume. His Hgb dropped from 12.6 to $11.3 \mathrm{~g} / \mathrm{dL}$ following the episode, which further dropped to $9.5 \mathrm{~g} / \mathrm{dL}$ within 24 hours. His prothrombin time was incalculably high. Warfarin was held, and he received desmopressin, prothrombin complex concentrate, and fresh frozen plasma. Upper endoscopy was deferred initially at the request of his health care proxy. Six days later, he experienced recurrent episodes of hematemesis with vomiting of approximately $500 \mathrm{~mL}$ of blood, leading to hypotension and a fall in Hgb from 8.3 to $7.5 \mathrm{~g} / \mathrm{dL}$ after the first episode. He received 8 units of packed red blood cells, was endotracheally intubated, and transferred to an intensive care unit. Upper endoscopy done at the bedside showed medium-sized varices in the proximal and mid esophagus with no stigmata of bleeding (Figure 4), a large amount of dark, clotted blood in the distal esophagus, and a likely visible vessel in the distal esophagus that was treated with placement of 3 clips. A single diminutive polyp was seen in the body of his stomach, with a large amount of dark, clotted blood in the fundus completely obscuring views in the area. The patient underwent an additional two upper endoscopy procedures to attempt to visualize the gastric fundus. During the final upper endoscopy, heater probe coagulation was applied to multiple areas of friable mucosa with superficial oozing in the gastric body. No intervention was performed for the visualized varices given no stigmata of recent bleeding.

Liver function tests at the time of his intensive care unit admission showed elevated aspartate aminotransferase (127 U/L) and alanine aminotransferase (98 U/L), which 


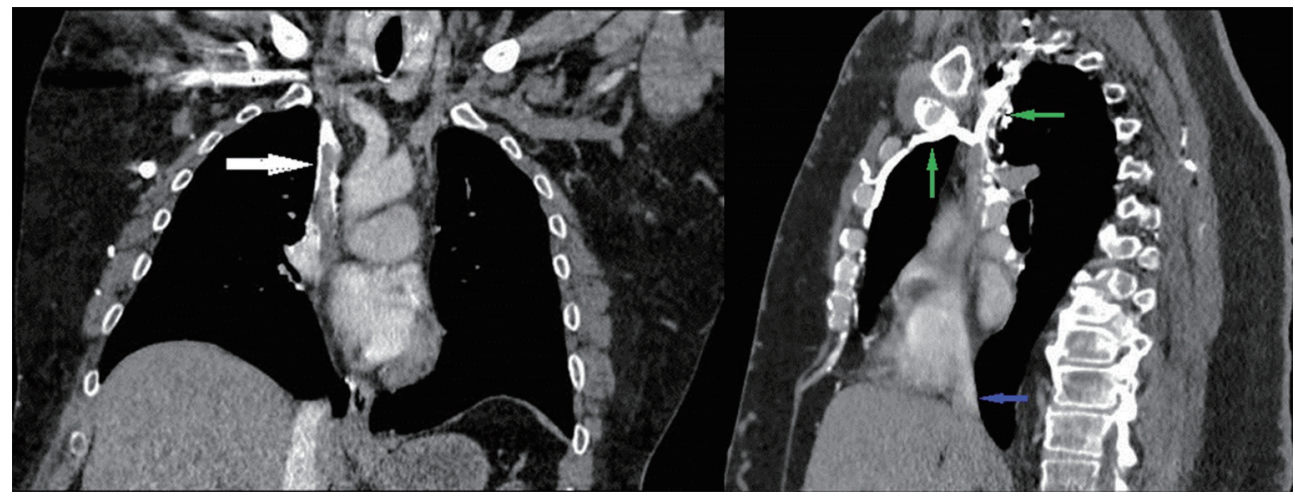

Figure 2 CT coronal section demonstrating occlusion of the superior vena cava (white arrow). CT sagittal section showing extensive collaterals (green arrows) and patent inferior vena cava (blue arrow).

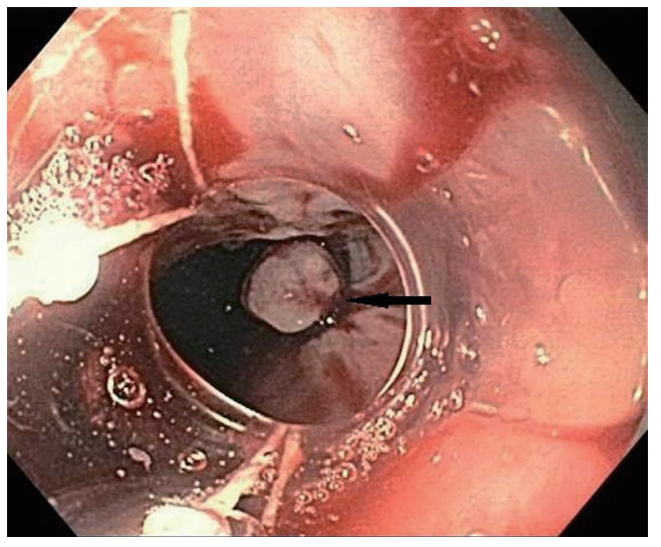

Figure 3 Band ligation of a varix (black arrow) was performed on the repeat upper endoscopy.

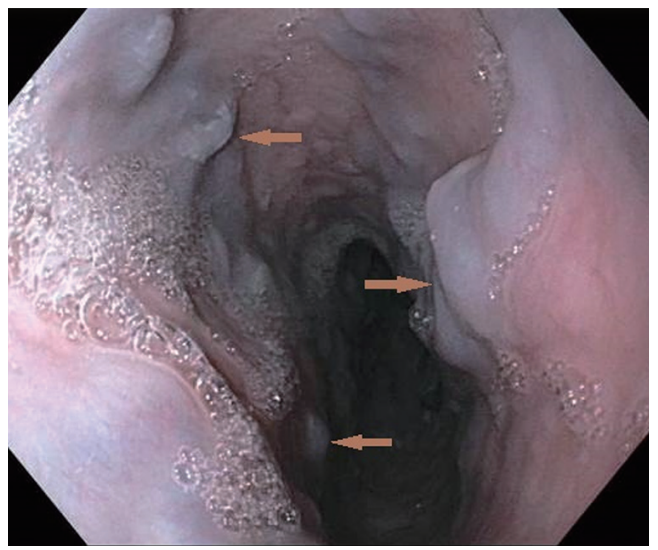

Figure 4 Upper endoscopy image showing medium-sized varices in the proximal and mid esophagus (brown arrows). No stigmata of bleeding was visualized.

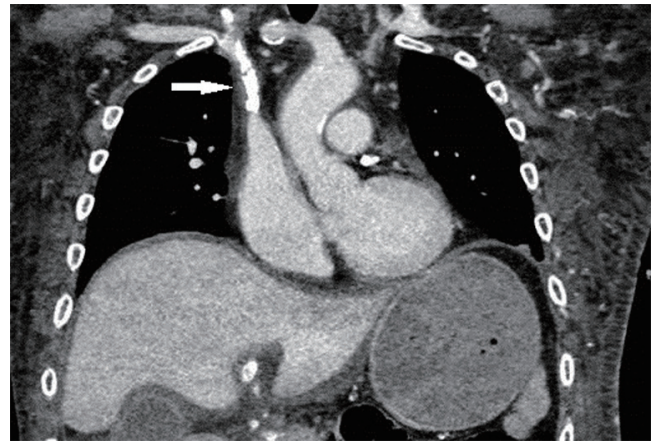

Figure 5 CT delayed contrast image demonstrating occlusion of the cranial superior vena cava (white arrow).

were normal at the time of admission. CT angiogram of the thorax, abdomen, and pelvis was performed to further evaluate for the source of bleeding, and showed chronic occlusion of the cranial SVC and distal left brachiocephalic vein, prominence of the azygous vein in the retroperitoneum and mediastinum entering the SVC, occlusion of the retrohepatic IVC and near occlusion of the intrahepatic IVC (Figures 5,6). The CT scan also showed mild hypertrophy of the caudate lobe possibly indicating underlying cirrhosis and portal vein collaterals around the spleen compatible with portal venous hypertension.

\section{Discussion}

\section{Pathogenesis}

Venous drainage of the esophagus predominantly occurs by the azygos and hemiazygos systems. When there is an obstruction, these vessels can dilate and form varices 
Page 4 of 6



Figure 6 Prominent azygous vein (blue arrow) noticed in the mediastinum on coronal section of CT angiogram of the thorax.

in the esophagus $(1,2)$. An obstruction in the SVC forces retrograde flow of blood into the right atrium through collateral channels to the IVC (1). If the obstruction is above the level of the azygous vein, blood flow back to the heart will be confined to the upper esophagus, leading to formation of varices in the upper third of the esophagus. In contrast, if the obstruction is below or involving the azygous vein, varices will form along the entire esophagus $(2,3)$.

\section{Etiology}

Downhill varices are also known as proximal esophageal varices (4). Thrombosis of the SVC is the most common etiology of downhill esophageal varices, but obstruction of the SVC can also be caused by severe pulmonary hypertension, thyroid tumors, Behçet's disease, abnormal cricopharyngeal muscle constriction, complications with HD catheters, mediastinal fibrosis, and surgical ligation of the SVC $(1,3,5)$. This is in contrast to uphill varices, which more commonly cause bleeding and are a result of portal hypertension (6). Based on a literature search, malignancy is described as the most common underlying etiology of SVC obstruction, accounting for up to $60 \%$ of cases but is only the cause of $14 \%$ of cases of downhill variceal bleeding. The most common cause of downhill variceal bleeding is complications related to venous catheters, most often seen in end- stage renal disease patients such as the two patients we presented (7). This finding can be attributed to the high rate of central venous narrowing from endothelial injury, turbulent blood flow, and tendency for thrombosis seen in patients on long-term HD (6).

Bleeding is a very rare presenting symptom for patients with downhill varices. In fact, downhill varices represent $0.4-10 \%$ of esophageal varices but less than $0.1 \%$ of patients presenting with hematemesis $(4,8)$. This may be attributed to the fact that downhill varices are located in the submucosa of the proximal esophagus, which are less susceptible to bleeding than uphill varices secondary to portal hypertension, which are located in the superficial subepithelium of the distal esophagus (3). Decreased gastric acid exposure may also contribute to the lower bleeding frequency of proximal esophageal varices (7).

\section{Diagnosis}

There are currently no guidelines on screening or management of downhill varices. Direct visualization of proximal varices is performed by upper endoscopy, which also allows intervention to be taken if necessary (8). Diagnosing the underlying cause of SVC obstruction can be done by various imaging modalities such as CT scan $(6,9)$.

\section{Treatment}

Treatment should be directed at the underlying cause of the obstruction of the SVC if possible. One case was reported, in which total thyroidectomy resulted in subsequent disappearance of varices in a patient who presented with massive bleeding from upper esophageal varices secondary to SVC obstruction by a malignant thyroid tumor (10). However, when this is not practical, low-risk cases can be managed conservatively, and patients at high risk of bleeding require aggressive management (4).

In the case of thrombosis of the SVC, chemical or mechanical thrombolysis of the clot, venoplasty, and stenting are some of the reported treatments to resolve obstruction. Stenting of the SVC was attempted in one of our cases by vascular surgery with no success. Vascular bypass has been attempted in appropriate surgical candidates. If obstruction is caused by compression from a tumor, steroids, chemotherapy, radiation, or resection of the tumor have been reported to relieve SVC obstruction (3).

In cases where there is high procedural risk or low probability of correcting the underlying medical disorder, there are other approaches to controlling downhill varices. Options include endoscopic band ligation, sclerotherapy, or balloon tamponade. These approaches should be attempted at the proximal end of the varix from which blood flow is supplied (7) (Table 2).

In our cases, the patients did not undergo endoscopic 
Table 2 List of cases reported in the literature

\begin{tabular}{|c|c|c|c|c|c|c|}
\hline Reference & $\begin{array}{l}\text { Age } \\
\text { (year) }\end{array}$ & $\begin{array}{l}\text { Admission } \\
\text { diagnosis }\end{array}$ & Site of lesion & $\begin{array}{l}\text { Number of } \\
\text { endoscopic } \\
\text { procedures }\end{array}$ & Intervention & $\begin{array}{l}\text { Proposed } \\
\text { etiology of } \\
\text { downhill varices }\end{array}$ \\
\hline Harwani et al. (2) & 55 & $\begin{array}{l}\text { Hematemesis } \\
\text { and melena }\end{array}$ & $\begin{array}{l}2 \text { columns of large varices extending } \\
\text { from post cricoid region downwards } \\
\text { to small varices in mid esophagus, } \\
3 \text { columns of large varices in lower } \\
\text { esophagus extending upwards }\end{array}$ & 1 & Variceal ligation & $\begin{array}{l}\text { Severe pulmonary } \\
\text { hypertension, } \\
\text { secondary to } \\
\text { rheumatic heart } \\
\text { disease }\end{array}$ \\
\hline Jammal (3) & 31 & $\begin{array}{l}\text { Abdominal } \\
\text { pain }\end{array}$ & $\begin{array}{l}\text { Small and medium varices in upper } \\
\text { and middle esophagus }\end{array}$ & 1 & Unknown & SVC thrombosis \\
\hline Rhoades et al. (4) & 57 & Hematemesis & At level of aortic arch & 1 & $\begin{array}{l}\text { Variceal } \\
\text { banding }\end{array}$ & Idiopathic \\
\hline Nguyen et al. (8) & 39 & Hematemesis & $\begin{array}{l}\text { Four columns of large esophageal } \\
\text { varices } 25 \mathrm{~cm} \text { to the distal esophagus, } \\
\text { just above the GE junction }\end{array}$ & 1 & $\begin{array}{l}\text { Balloon dilation } \\
\text { SVC }\end{array}$ & SVC occlusion \\
\hline Froilán et al. (9) & 49 & Hematemesis & $\begin{array}{l}\text { Grade } 2 \text { esophageal varices confined } \\
\text { to the proximal and mid esophagus }\end{array}$ & 1 & $\begin{array}{l}\text { Sclerotherapy } \\
\text { of varices, SVC } \\
\text { stenting }\end{array}$ & SVC occlusion \\
\hline Vorlop et al. (11) & 42 & Hematemesis & Proximal & 1 & $\begin{array}{l}\text { Angioplasty and } \\
\text { stenting SVC }\end{array}$ & SVC occlusion \\
\hline $\begin{array}{l}\text { Tavakkoli } \\
\text { et al. (12) }\end{array}$ & 42 & $\begin{array}{l}\text { Superior vena } \\
\text { cava syndrome }\end{array}$ & Upper third of esophagus & 1 & Variceal ligation & SVC thrombosis \\
\hline $\begin{array}{l}\text { Berkowitz } \\
\text { et al. (16) }\end{array}$ & 32 & $\begin{array}{l}\text { Hematemesis } \\
\text { and melena }\end{array}$ & $\begin{array}{l}\text { Grade } 2 / 3 \text { esophageal varices in } \\
\text { upper and mid esophagus }\end{array}$ & 1 & Ligation & SVC occlusion \\
\hline
\end{tabular}

SVC, superior vena cava.

treatment for their varices initially as active sites of bleeding were not found during endoscopy. One patient did undergo EGD with banding eventually as outlined above.

\section{Complications}

There are many complications associated with treating downhill esophageal varices. Endoscopic therapy to ligate or band the varices has a higher risk of complications in patients with varices in the upper esophagus compared with those more distally (1). The risk of bleeding or perforation is higher in banding in the upper esophagus due to weakness of the proximal esophageal posterior wall and overall lack of serosa $(3,17)$. Nevertheless, banding of varices is preferred to sclerotherapy because of the potential risk of spinal cord infarction with sclerotherapy caused by retrograde flow of sclerosant to spinal veins when injected at the level of the middle and upper esophagus (11). In one case, sclerotherapy was preferred over banding due to the very proximal localization of bleeding just below the upper esophageal 
sphincter, where restricted field of work made banding impossible to perform (9). Some other complications that have been reported include vertebral infarction thought to be caused by retrograde flow of the sclerosing agent into the vertebral vasculature. There was also a reported case of cardiovascular failure due to massive pulmonary embolism following endoscopic injection with polidocanol and cyanoacrylate (1).

\section{Conclusions}

It should be kept in mind that a patient presenting with hematemesis or melena without any stigmata of liver disease should be further evaluated for any obstruction to the SVC. Upper esophageal varices are often a result of SVC obstruction and when feasible management should be directed at treating the underlying cause of obstruction.

\section{Acknowledgements}

None.

\section{Footnote}

Conflicts of Interest: The authors have no conflicts of interest to declare.

Informed Consent: Written informed consent was obtained from the patients for publication of this manuscript and any accompanying images.

\section{References}

1. Areia M, Romãozinho JM, Ferreira M, et al. "Downhill" varices. A rare cause of esophageal hemorrhage. Rev Esp Enferm Dig 2006;98:359-61.

2. Harwani YP, Kumar A, Chaudhary A, et al. Combined uphill and downhill varices as a consequence of rheumatic heart disease: a unique presentation. J Clin Exp Hepatol 2014;4:63-5.

3. Jammal GE. An unusual case of Esophageal Varices: "Downhill" type. Gastroenterol Hepatol Open Access 2015;2:00040.

4. Rhoades DP, Forde KA, Tabibian JH. Proximal Esophageal Varices: A Rare Yet Treatable Cause of Hemorrhage. Clin Gastroenterol Hepatol 2016;14:e105-6.

5. Sheiner NM, Palayew MJ. "Downhill" esophageal varices in superior vena caval obstruction. Can Med Assoc J 1969;100:961-4.
6. Siegel Y, Schallert E, Kuker R. Downhill esophageal varices: a prevalent complication of superior vena cava obstruction from benign and malignant causes. J Comput Assist Tomogr 2015;39:149-52.

7. Loudin M, Anderson S, Schlansky B. Bleeding 'downhill' esophageal varices associated with benign superior vena cava obstruction: case report and literature review. BMC Gastroenterol 2016;16:134.

8. Nguyen LP, Sriratanaviriyakul N, Sandrock C. A Rare but Reversible Cause of Hematemesis: "Downhill" Esophageal Varices. Case Rep Crit Care 2016;2016:2370109.

9. Froilán C, Adán L, Suárez JM, et al. Therapeutic approach to "downhill" varices bleeding. Gastrointest Endosc 2008;68:1010-2.

10. Johnson LS, Kinnear DG, Brown RA, et al. 'Downhill' esophageal varices. A rare cause of upper gastrointestinal bleeding. Arch Surg 1978;113:1463-4.

11. Vorlop E, Zaidman J, Moss SF. Clinical challenges and images in GI. Downhill esophageal varices secondary to superior vena cava occlusion. Gastroenterology 2008;135:1863, 2158.

12. Tavakkoli H, Asadi M, Haghighi M, et al. Therapeutic approach to "downhill" esophageal varices bleeding due to superior vena cava syndrome in Behcet's disease: a case report. BMC Gastroenterol 2006;6:43.

13. Bédard EL, Deslauriers J. Bleeding "downhill" varices: a rare complication of intrathoracic goiter. Ann Thorac Surg 2006;81:358-60.

14. Colak B, Erda H, Arhan M, et al. A Case of Downhill Esophageal Varices Associated with Superior Vena Cava Syndrome due to Mediastinal Mass. Euroasian J HepatoGastroenterol 2012;2:107-8.

15. Nayudu SK, Dev A, Kanneganti K. "Downhill" Esophageal Varices due to Dialysis Catheter-Induced Superior Vena Caval Occlusion: A Rare Cause of Upper Gastrointestinal Bleeding. Case Rep Gastrointest Med 2013;2013:830796.

16. Berkowitz JC, Bhusal S, Desai D, et al. Downhill Esophageal Varices Associated With Central Venous Catheter-Related Thrombosis Managed With Endoscopic and Surgical Therapy. ACG Case Rep J 2016;3:e102.

17. Dhawan SS. "Downhill" varices--banding proximal to varix?. Ann Thorac Surg 2007;83:359-60.

Cite this article as: Chakinala RC, Kumar A, Barsa JE, Mehta D, Haq KF, Solanki S, Tewari V, Aronow WS. Downhill esophageal varices: a therapeutic dilemma. Ann Transl Med 2018;6(23):463. doi: 10.21037/atm.2018.11.13 